\title{
気体浸透と熱伝導のもとで多孔質無限体に生じる熱応力場の基本解*
}

荒井 正行 ${ }^{* 1}$

\section{Fundamental solution of thermal stress field in porous infinite media subjected to gas infiltration and heat transfer}

\author{
Masayuki ARAI ${ }^{* 1}$ \\ ${ }^{* 1}$ Tokyo University of Science. Dept. of Mechanical Engineering \\ 6-3-1, Niijyuku, Katsushika-ku, Tokyo, 125-8585, Japan
}

\section{Received 13 September 2013}

\begin{abstract}
When a porous solid is subjected to both gas infiltration and heat transfer, thermal stresses are generated in such a solid. In the previous reports, fundamental theory for a porous solid under such a complex situation was developed, and then a thermal stress problem for a porous solid with a flat boundary surface subjected to a concentrated loading was solved completely. In this study, thermal stress problem for a porous infinite solid subjected to a point loading is investigated. A method of solution based upon displacement potential and Fourier integral transform techniques is applied to solve the problem as well as the way used in the previous report. Complete closed form of gas pressure, solid temperature, displacement and thermal stress field in the infinite porous media are presented. It was found that the asymptotic behavior around a point load is strongly affected by gas permeability and pressure of gas phase.
\end{abstract}

Key Words : Elasticity, Porous solid, Gas infiltration, Heat transfer, Thermal stress, Infinite problem, Green function

\section{1. 緒言}

著者は，これまでに高温（あるいは低温）の気体が多孔質体中を浸透するときの熱弾性理論について検討して きた(荒井, 2012). 例えば，多孔質体中を高温気体が浸透すると気孔壁面を介して気体の熱が固体に伝わることに なる. 力学的には，気孔壁面に作用する気体圧力と固体温度の変化に起因して多孔質体は膨張することになる. そしてこのような膨張が拘束される場合には，多孔質体には熱応力が生じることになる．これまでの研究(荒井， 2012,2013)においては，気体の流れ場と熱伝導場が定常状態に達したときの熱応力の数学的解法について取り組 んできた。すなわち，多孔質体中を浸透する気体圧力 $(P)$ が Laplace 方程式を満足すること，固体温度 $\left(t_{s}\right)$ と気体 圧力の二乗の和で与えられる物理量 $(\Phi)$ が Laplace 方程式を満足することを示した．また，気体の浸透と熱伝導を 受けた多孔質体における自由膨張項は, 固体温度の変化により生じる熱膨張 $\left(\alpha t_{s}\right)$ と気孔壁面に作用する気体の膨 張のふたつの効果を含むことも示してきた．固体温度場は気体圧力の二乗項からなる非線形項を含むため一般に は熱応力の厳密解を求めることは困難である。しかしならが，いくつかの単純な形状と境界条件の問題に対して は厳密解を求めることができる，既報(荒井, 2013)においては，二次元多孔質半無限体の自由表面上において気体 圧力，温度を集中して受けるときの定常熱応力解について示した．これにより，気体による自由膨張効果によっ て多孔質体には熱応力が生じること，気体の透過係数に伴って熱応力が増加することを明らかにした．

本研究では，多孔質無限体中において点状に気体圧力・温度が作用するときの定常熱応力場に対する基本解を 示す. 周知のように，基本解とは無限体において集中源（Source）が存在するとき，この源が周囲にどのような 影響を及ぼすのかを意味しており，これはまた Green 関数とも呼ばれている。これまでに様々な場の支配方程式

\footnotetext{
* 論文 No.13-00703 [DOI: 10.1299/transjsme.2014smm0086]

${ }^{* 1}$ 正員, 東京理科大学工学部第一部機械工学科（广125-8585 東京都葛飾区新宿 6-3-1）

E-mail:marai@rs.tus.ac.jp
} 
に対する基本解が求められてきた。代表的な解として，Laplace 方程式に対しては Kellogg の解(Kellog, 1953)，物 体力がない弾性体における Navier の式に対しては Kelvin 解(Jaswon and Symm, 1977)がある．そして，これらの解 の無限集合として構成される積分方程式法(Jaswon and Symm, 1977)に基づいて一般的な境界条件のもとで様々な 問題を解くことが可能となる.

\section{2. 基礎式}

気体が非圧縮性，Darcy の法則が成立するものと仮定すれば，直角座標系 $x_{i} \in \mathbb{R}^{2}$ において，気体圧力 $P\left(x_{i}\right)$ に関 する方程式は，

$$
\partial_{1}^{2} P+\partial_{2}^{2} P=0
$$

また，気体圧力と固体温度 $t_{s}\left(x_{i}\right)$ の連成方程式は，

$$
\partial_{1}^{2} \Phi+\partial_{2}^{2} \Phi=0
$$

となる.ここで, $\partial_{i}=\partial / \partial x_{i}$,

$$
\Phi=t_{s}+\omega P^{2}
$$

ならびに，

$$
\omega=\frac{c_{p}}{2 R k_{s}}\left(\frac{\kappa}{\zeta}\right)
$$

であり, $c_{p}$ は定圧比熱, $R$ はガス定数, $k_{s}$ は多孔質体のみかけの熱伝導率(荒井, 2012), $(\kappa / \zeta)$ は多孔質体中の気体 の透過係数である.

つぎに，二次元熱応力問題に対する Navier の式は，

$$
\partial_{i} \partial_{i} u_{j}+\frac{\chi_{1}-(n-2) \chi_{2}}{\chi_{1}-n \chi_{2}} \partial_{j} e=\frac{\chi_{1}}{\chi_{1}-n \chi_{2}} \partial_{j} F
$$

で与えられる，ここで， $u_{j}$ は変位成分，

$$
\begin{aligned}
& \chi_{1}=1+15\left(\frac{1-v}{7-5 v}\right) \phi \\
& \chi_{2}=\frac{1}{1+v}+\frac{3}{2}\left(\frac{1-v}{1+v}\right)\left(\frac{1+5 v}{7-5 v}\right) \phi
\end{aligned}
$$

, $v$ はポアソン比, $\phi$ は気孔率, 平面応力問題に対しては $n=2$, 平面ひずみ問題に対しては $n=3$ をる. また,

$$
e=\partial_{i} u_{i}
$$

さらに, 


$$
F=3\left(\frac{\phi}{\mu}\right) P+2 \alpha t_{s}
$$

である.ここで， $\mu$ は横弾性係数， $\alpha$ は熱膨張係数である.

変位ポテンシャル関数 $\psi\left(x_{i}\right)$ を利用して変位成分を,

$$
u_{i}=\partial_{i} \psi
$$

のようにおく.これを式(5)に代入することで $\psi$ はつぎの偏微分方程式を満足していなければならないことがわか る.

$$
\partial_{i} \partial_{i} \psi=\frac{\chi_{1} F}{2\left(\chi_{1}-(n-1) \chi_{2}\right)}
$$

\section{3. 点状圧カ・温度を受ける多孔質無限体問題の解法とその基本解}

点状圧力・温度を受ける多孔質無限体の熱忘力問題を解くために，(a)点状気体圧力の問題，(b) 点状固体温度 の問題, (c)気体と温度の膨張によって生じる応力の問題の 3 つの問題に分離する.

本研究では, Sneddonにより導入されたつぎの二重 Fourier 変換法(Sneddon, 1995)に従い, 偏微分方程式を解く.

$$
\begin{aligned}
& \mathcal{F}\left[f\left(x_{1}, x_{2}\right)\right]=\hat{f}\left(\xi_{1}, \xi_{2}\right)=\int_{-\infty}^{\infty} \int_{-\infty}^{\infty} f\left(x_{1}, x_{2}\right) \exp \left(i \xi_{i} x_{i}\right) d x_{1} d x_{2} \\
& \mathcal{F}^{-1}\left[\hat{f}\left(\xi_{1}, \xi_{2}\right)\right]=f\left(x_{1}, x_{2}\right)=\left(\frac{1}{2 \pi}\right)^{2} \int_{-\infty}^{\infty} \int_{-\infty}^{\infty} \hat{f}\left(\xi_{1}, \xi_{2}\right) \exp \left(-i \xi_{i} x_{i}\right) d \xi_{1} d \xi_{2}
\end{aligned}
$$

ここで, 原関数 $f$ に対して像関数には・を付けることでそれぞれの関数を区別する. また, $\xi_{i} x_{i}=\xi_{1} x_{1}+\xi_{2} x_{2}$ であ る.

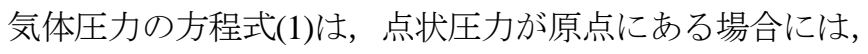

$$
\partial_{1}^{2} P+\partial_{2}^{2} P+p_{0} \delta\left(x_{1}\right) \delta\left(x_{2}\right)=0
$$

ここで， $\delta(\cdot)$ は Dirac のデルタ関数である. 式(12)を Fourier 変換すると,

$$
\hat{P}\left(\xi_{1}, \xi_{2}\right)=\frac{p_{0}}{\xi_{1}^{2}+\xi_{2}^{2}}
$$

この逆 Fourier 変換は,

$$
P\left(x_{1}, x_{2}\right)=\left(\frac{1}{2 \pi}\right)^{2} p_{0} \int_{-\infty}^{\infty} \int_{-\infty}^{\infty} \frac{\exp \left(-i \xi_{i} x_{i}\right)}{\xi_{1}^{2}+\xi_{2}^{2}} d \xi_{1} d \xi_{2}
$$

となり，無限積分を実行することで気体圧力解 


$$
P\left(x_{1}, x_{2}\right)=\frac{1}{2 \pi} p_{0} \ln \left(\frac{1}{x_{1}^{2}+x_{2}^{2}}\right)^{\frac{1}{2}}
$$

を得る.

点状圧力が $x_{i}=\alpha_{i}$ にあるときには, 座標系の平行移動 $x_{i} \rightarrow\left(x_{i}-\alpha_{i}\right)$ を行うことで, 気体圧力に関する基本解 $P\left(x_{1}, x_{2} \mid \alpha_{1}, \alpha_{2}\right)$

$$
P\left(x_{1}, x_{2} \mid \alpha_{1}, \alpha_{2}\right)=\frac{1}{2 \pi} p_{0} \ln \left(\frac{1}{\left(x_{1}-\alpha_{1}\right)^{2}+\left(x_{2}-\alpha_{2}\right)^{2}}\right)^{\frac{1}{2}}
$$

を得ることができる。

気体圧力と固体温度の連成方程式(2)は,

$$
\partial_{1}^{2} \Phi+\partial_{2}^{2} \Phi+\Phi_{0} \delta\left(x_{1}\right) \delta\left(x_{2}\right)=0
$$

ここで， $\Phi_{0}=t_{0}+\omega p_{0}^{2}$ である. 式(12)とのアナロジーを利用すれば，式(15)の解は，

$$
\Phi\left(x_{1}, x_{2}\right)=\frac{1}{2 \pi} \Phi_{0} \ln \left(\frac{1}{x_{1}^{2}+x_{2}^{2}}\right)^{\frac{1}{2}}
$$

となって, 固体温度解

$$
t_{s}\left(x_{1}, x_{2}\right)=\frac{1}{2 \pi}\left(t_{0}+\omega p_{0}^{2}\right) \ln \left(\frac{1}{x_{1}^{2}+x_{2}^{2}}\right)^{\frac{1}{2}}-\frac{\omega p_{0}^{2}}{(2 \pi)^{2}}\left[\ln \left(\frac{1}{x_{1}^{2}+x_{2}^{2}}\right)^{\frac{1}{2}}\right]^{2}
$$

を得る. なお，点状温度が $x_{i}=\alpha_{i}$ にあるときには，座標系の平行移動 $x_{i} \rightarrow\left(x_{i}-\alpha_{i}\right)$ を行うことで固体温度に関す る基本解 $t_{s}\left(x_{1}, x_{2} \mid \alpha_{1}, \alpha_{2}\right)$ を得ることができる. 寸なわち,

$$
t_{s}\left(x_{1}, x_{2} \mid \alpha_{1}, \alpha_{2}\right)=\frac{1}{2 \pi}\left(t_{0}+\omega p_{0}^{2}\right) \ln \left(\frac{1}{\left(x_{1}-\alpha_{1}\right)^{2}+\left(x_{2}-\alpha_{2}\right)^{2}}\right)^{\frac{1}{2}}-\frac{\omega p_{0}^{2}}{(2 \pi)^{2}}\left[\ln \left(\frac{1}{\left(x_{1}-\alpha_{1}\right)^{2}+\left(x_{2}-\alpha_{2}\right)^{2}}\right)^{\frac{1}{2}}\right]^{2}
$$

熱応力問題は，式(9)を解けばよい，まず，式(13)と式(17)を式(9)に代入して,

$$
2(1-(n-1) \bar{v}) \partial_{i} \partial_{i} \psi=-k_{1} \ln \left(x_{1}^{2}+x_{2}^{2}\right)-k_{2}\left\{\ln \left(x_{1}^{2}+x_{2}^{2}\right)^{2}\right\}^{2}
$$

ここで, $\bar{v}=\chi_{2} / \chi_{1}$ であり, また

$$
\begin{aligned}
& k_{1}=\frac{1}{2 \pi}\left[\frac{3}{2}\left(\frac{\phi}{\mu}\right) p_{0}+\alpha\left(t_{0}+\omega p_{0}^{2}\right)\right] \\
& k_{2}=\frac{1}{2}\left(\frac{1}{2 \pi}\right)^{2} \alpha \omega p_{0}^{2}
\end{aligned}
$$


である. 式(19)は容易に解くことができて，

$$
\begin{aligned}
& 2(1-(n-1) \bar{v}) \psi \\
& \qquad m_{1}\left(x_{1}^{2}+x_{2}^{2}\right)\left[\frac{1}{2} \ln \left(x_{1}^{2}+x_{2}^{2}\right)-1\right]+m_{2}\left(x_{1}^{2}+x_{2}^{2}\right)\left[\left(\frac{1}{2} \ln \left(x_{1}^{2}+x_{2}^{2}\right)\right)^{2}-\frac{1}{2} \ln \left(x_{1}^{2}+x_{2}^{2}\right)+\frac{1}{2}\right]
\end{aligned}
$$

となることは，式(20)を式(19)に代入すれば容易に確認できる．ここで，

$$
\begin{aligned}
& m_{1}=-\frac{1}{4 \pi}\left[\frac{3}{2}\left(\frac{\phi}{\mu}\right) p_{0}+\alpha\left(t_{0}+\omega p_{0}^{2}\right)\right]+\frac{1}{2}\left(\frac{1}{2 \pi}\right)^{2} \alpha \omega p_{0}^{2} \\
& m_{2}=-\frac{1}{2}\left(\frac{1}{2 \pi}\right)^{2} \alpha \omega p_{0}^{2}
\end{aligned}
$$

\section{である.}

変位成分は, $u_{i}=\partial_{i} \psi$ より得られ，

$$
\begin{aligned}
& 2(1-(n-1) \bar{v}) u_{1}=m_{1} x_{1}\left(\ln \left(x_{1}^{2}+x_{2}^{2}\right)-1\right)+\frac{1}{2} m_{2} x_{1}\left[\ln \left(x_{1}^{2}+x_{2}^{2}\right)\right]^{2} \\
& 2(1-(n-1) \bar{v}) u_{2}=m_{1} x_{2}\left(\ln \left(x_{1}^{2}+x_{2}^{2}\right)-1\right)+\frac{1}{2} m_{2} x_{2}\left[\ln \left(x_{1}^{2}+x_{2}^{2}\right)\right]^{2}
\end{aligned}
$$

応力成分は,

$$
\begin{aligned}
& \frac{1}{2 \mu} \chi_{1} \sigma_{11}=-\partial_{2}^{2} \psi \\
& \frac{1}{2 \mu} \chi_{1} \sigma_{22}=-\partial_{1}^{2} \psi \\
& \frac{1}{2 \mu} \chi_{1} \sigma_{12}=\partial_{1} \partial_{2} \psi
\end{aligned}
$$

よりつぎのように得られる.

$$
\begin{aligned}
& \frac{1-(n-1) \bar{v}}{2 \mu} \chi_{1} \sigma_{11}=-m_{1}\left\{\ln \left(x_{1}^{2}+x_{2}^{2}\right)^{\frac{1}{2}}+\frac{1}{2}\left(\frac{x_{2}^{2}-x_{1}^{2}}{x_{1}^{2}+x_{2}^{2}}\right)\right\}-m_{2}\left\{\ln \left(x_{1}^{2}+x_{2}^{2}\right)^{\frac{1}{2}}+\frac{2 x_{2}^{2}}{x_{1}^{2}+x_{2}^{2}}\right\} \ln \left(x_{1}^{2}+x_{2}^{2}\right)^{\frac{1}{2}} \\
& \frac{1-(n-1) \bar{v}}{2 \mu} \chi_{1} \sigma_{22}=-m_{1}\left\{\ln \left(x_{1}^{2}+x_{2}^{2}\right)^{\frac{1}{2}}+\frac{1}{2}\left(\frac{x_{1}^{2}-x_{2}^{2}}{x_{1}^{2}+x_{2}^{2}}\right)\right\}-m_{2}\left\{\ln \left(x_{1}^{2}+x_{2}^{2}\right)^{\frac{1}{2}}+\frac{2 x_{1}^{2}}{x_{1}^{2}+x_{2}^{2}}\right\} \ln \left(x_{1}^{2}+x_{2}^{2}\right)^{\frac{1}{2}} \\
& \frac{1-(n-1) \bar{v}}{2 \mu} \chi_{1} \sigma_{12}=\left\{m_{1}+2 m_{2} \ln \left(x_{1}^{2}+x_{2}^{2}\right)^{\frac{1}{2}}\right\} \frac{x_{1} x_{2}}{x_{1}^{2}+x_{2}^{2}}
\end{aligned}
$$

なお, 点状圧力・温度が $x_{i}=\alpha_{i}$ にあるときには, 座標系の平行移動 $x_{i} \rightarrow\left(x_{i}-\alpha_{i}\right)$ を行うことで応力成分に関する 基本解 $\sigma_{i j}\left(x_{1}, x_{2} \mid \alpha_{1}, \alpha_{2}\right)$ が得られる. 


\section{4. 数値計算例}

数值計算結果の一例を示寸. ここでは, 集中源近傍での固体温度 $\left(t_{s} / t_{0}\right)$, ならびに応力成分 $\left(\frac{1-(n-1) \bar{v}}{2 \mu} \chi_{1} \sigma_{i j}\right)$ の $x_{2}=0$ 面上での分布について調べた．本計算において集中源は座標系の原点にあるものとした．また，本計算に 用いた物性值を表 1 (荒井, 2012) に示寸. 集中源に対しては温度 $t_{0}=500 \mathrm{~K}$, 圧力 $p_{0}=4 \times 10^{5} \mathrm{~Pa}$ を与え, 多孔質 体の気孔率を $\phi=0.4$ で固定して透過係数を $\kappa / \varsigma=5 \times 10^{-10}, 3 \times 10^{-10}, 5 \times 10^{-11}$ と変化させた.

Table 1 Physical parameters employed in this calculation (荒井，2012)

\begin{tabular}{ccc}
\hline Nomenclature & Symbol & Assumed value \\
\hline Specific heat & $c_{p}[\mathrm{~J} / \mathrm{kg} \mathrm{K}]$ & 1000 \\
Gas density & $\rho\left[\mathrm{kg} / \mathrm{m}^{3}\right]$ & 1.3 \\
\hline Gas constant & $R[\mathrm{~J} / \mathrm{kg} \mathrm{K}]$ & 287.03 \\
\hline Thermal conductivity of matrix & $\lambda_{s}[\mathrm{~W} / \mathrm{mK}]$ & 1.0 \\
\hline Elastic modulus & $E[\mathrm{GPa}]$ & 40.0 \\
\hline Poisson's ratio & $v$ & 0.3 \\
\hline Coefficient of thermal expansion & $\alpha[1 / \mathrm{K}]$ & $20 \times 10^{-6}$ \\
\hline
\end{tabular}

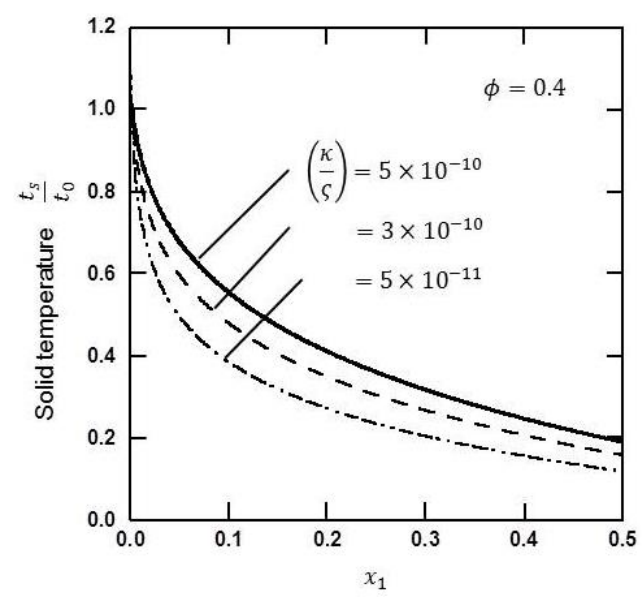

Fig.1 Solid temperature distribution near a point loading

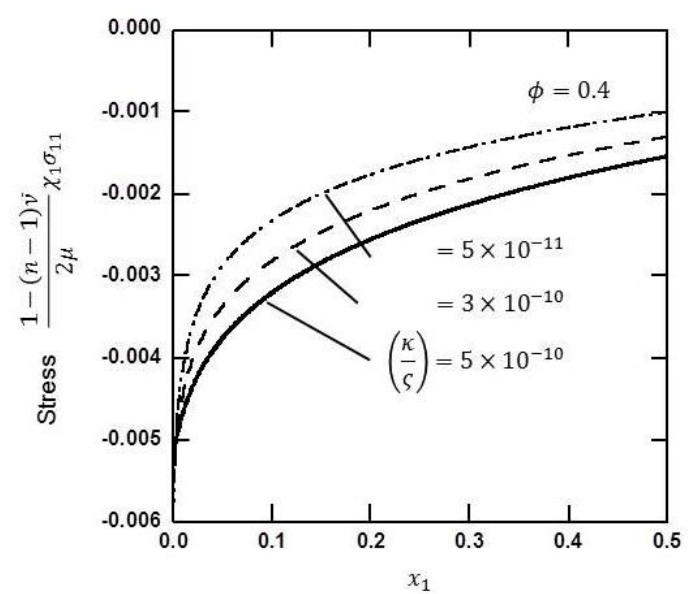

(a) $\sigma_{11}$ component

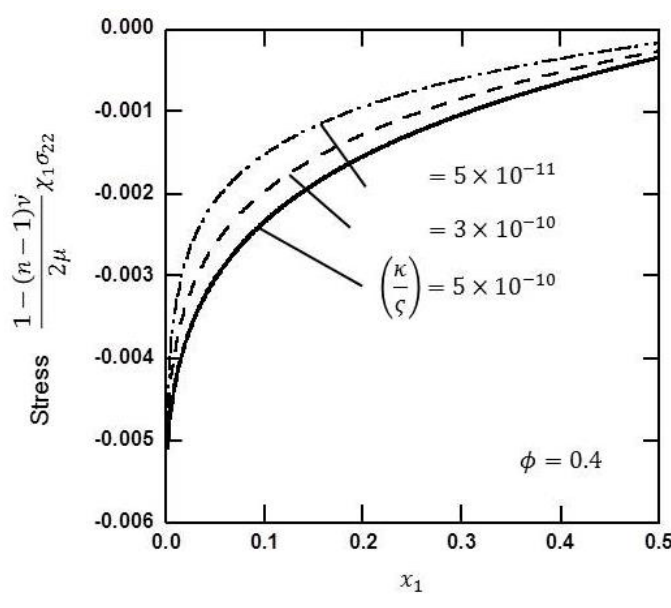

(b) $\sigma_{22}$ component

Fig.2 Stress distribution near a point loading 
図 1，2 に得られた計算結果を示寸. 図 1 は固体温度分布, 図 2 は応力分布である. 固体温度は集中源で無限大 となり, 集中源から離れるにつれて緩やか低下していく.また, 気体の透過係数が増加するにつれて固体温度も 高くなることがわかる. 垂直応力成分においては，多孔質体の 1 点が集中的に加熱，加圧されているために圧縮 応力となる. さらに, 固体温度と同様に集中源で応力は無限大となり, 集中源から離れるにつれて応力は低下し ていく．また，気体の透過係数に伴って応力も増加する.

\section{5. 考察}

つぎにここに得られた気体圧力，固体温度，熱応力に関する基本解の漸近挙動について考察しておく．気体圧 力解は, $\forall r=\sqrt{x_{i} x_{i}}$ に対して

$$
P(r) \in O\left(\ln \frac{1}{r}\right)
$$

により解の性質をランダウ記号 $O(-)$ にって特徵付けられる. これにより, この解の振る舞いは圧力 $p_{0}$ の大きさ に依存する．すなわち点状圧力の大きさが強くなるにつれてより広い領域まで圧力の変化の影響を受けるように なる.

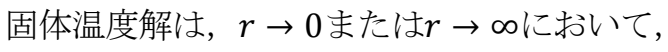

$$
t_{s}(r) \in O\left(\left[\ln \frac{1}{r}\right]^{2}\right)
$$

のように漸近する. この解の振る舞いは熱交換パラメータののうち項 $\omega p_{0}^{2}$ のきさに依存する. すなわち, 点状 圧力の大きさが強く，また気体の透過係数が増加寸るにつれて固体温度が高くなる．これは，先に示した計算結 果の図 1 と対応しており, 物理的には気孔内の気体温度が固体温度と効率よく熱交換することを意味する.

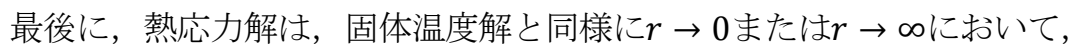

$$
\sigma_{i j}(r) \in O\left(\left[\ln \frac{1}{r}\right]^{2}\right)
$$

のように漸近し，この解の振る舞いは項 $\omega p_{0}^{2}$ に熱膨張係数 $\alpha$ を乗じた大きさに依存して変化する.よって, 多孔質 無限体に生じる熱応力は, 主に気体の透過係数, 気体圧力の二乗と熱膨張係数を相互に乗じたものを熱伝導率で 除した量に強く影響を受けていることがわかる．これは，先に示した図 2 の傾向と対応している.

\section{6. 結}

本論文では，多孔質無限体中において点状に気体圧力・温度が作用寸るときの気体圧力，固体温度，熱応力に 対する基本解を求めた. それらの漸近挙動を調べた結果, 多孔質体に生じる熱応力は, 主に気体の透過係数, 気 体圧力の二乗と熱膨張係数を相互に乗じた量に強く影響を受けていることがわかった.

\section{文献}

荒井正行, 気体浸透と熱伝導を受ける多孔質体の熱忘力について, 日本機械学会論文集 A 編, Vol.78, No.787

(2011), p.336-348. 
荒井正行, 気体浸透と熱伝導を受ける多孔質半無限体の熱応力, 日本機械学会論文集 A 編, Vol.79, No.800 (2012), p.463-476.

Kellogg, O. D., Foundations of potential theory (1953), pp. 121-124, Dover Publications.

Jaswon, M. A. and Symm, G. T., Integral equation methods in potential theory and elastostatics (1977a), pp.83-85, Academic Press.

Jaswon, M. A. and Symm, G. T., Integral equation methods in potential theory and elastostatics (1977b), pp.153-171, Academic Press.

Sneddon, I.N., Fourier transforms (1995), pp.7-29, Dover Publications.

\section{References}

Arai, M., On thermal stress in porous solid under gas infiltration and heat transfer, Transactions of the Japan Society of Mechanical Engineers, Series A, Vol. 78, No. 787 (2011), pp.336-348 (in Japanese).

Arai, M., Thermal stress of porous semi infinite media subjected to gas infiltration and heat transfer, Transactions of the Japan Society of Mechanical Engineers, Series A, Vol. 79, No. 800 (2012), pp.463-476 (in Japanese).

Kellogg, O. D., Foundations of potential theory (1953), pp. 121-124, Dover Publications.

Jaswon, M. A. and Symm, G. T., Integral equation methods in potential theory and elastostatics (1977a), pp.83-85, Academic Press.

Jaswon, M. A. and Symm, G. T., Integral equation methods in potential theory and elastostatics (1977b), pp.153-171, Academic Press.

Sneddon, I.N., Fourier transforms (1995), pp.7-29, Dover Publications. 